\title{
Effect of ADCON-L on adjustable strabismus surgery in rabbits
}

\author{
Mi Young Choi, Soo-Jae Auh, Dong Gyu Choi, Bong Leen Chang
}

\begin{abstract}
Backgroundlaims-In search of a way to prevent postoperative adhesion after strabismus surgery, an animal study was performed to assess the effect of a gel consisting of a polyglycan ester in a gelatin matrix (ADCON-L).

Methods-Bilateral recessions of superior rectus muscle (SR) were performed on 16 rabbits. ADCON-L was applied beneath and over the SR in the right eyes of all rabbits, while the operative fields in the left eyes were irrigated with a balanced salt solution (BSS). The adjustment was performed on each SR at 4 and 7 days postoperatively on the same eye. The length and force of the adjustment and the degree of adhesion were recorded. At 3 weeks postoperatively, disinsertional force was measured in several of the eyes, and the other eyes were enucleated.

Results-The length of the adjustment was longer and the force of the adjustment was less in the ADCON-L group than in the BSS treated group at 4 and 7 days postoperatively $(p=0.00)$. A significant reduction $(p=0.00)$ in the degree of adhesion was noted in eyes treated with ADCON-L. There was no significant difference in disinsertional force between the two groups. Histopathological evaluation of the muscle revealed decreased fibrosis of perimuscular connective tissue in eyes treated with ADCON-L at 3 weeks postoperatively.

Conclusion-This study suggests that ADCON-L helps to prevent postoperative adhesion in rabbits and enables adjustment twice within 7 days postoperatively without complications.

(Br f Ophthalmol 2001;85:80-84)
\end{abstract}

Postoperative adhesion occurs when there is proliferation of fibroblasts and biosynthesis of collagen and extracellular matrix. It may result from direct tissue trauma, excessive bleeding, multiple operations, reactions to suture materials, and postoperative infection. ${ }^{1}$ The adhesion often hinders the ability to predict surgical results and to perform adjustments after strabismus surgery. Adjustable sutures are intended primarily to facilitate more accurate ocular alignment and decrease the need for reoperation..$^{2-7}$ Therefore, several approaches to preventing the formation of adhesion have been explored.

Careful and atraumatic surgical techniques are the most effective means of preventing postoperative adhesion. Nevertheless, postop- erative adhesions may occur in patients at high risk of exaggerated scarring, especially in cases involving multiple reoperations or after scleral buckling surgery. Therefore, a variety of mechanical barriers ${ }^{18-15}$ and antiproliferative agents $^{816-18}$ have been investigated in animal models for their potential to inhibit adhesion after strabismus surgery.

Recently, a gel consisting of a polyglycan ester in a gelatin matrix (ADCON-L; Gliatech Inc, Cleveland, $\mathrm{OH}$, USA) was used to minimise adhesion after spine surgery. ${ }^{19}$ ADCON-L functions as a barrier to fibroblasts. It is biodegradable, does not incite inflammatory reactions, and disappears completely within 3 weeks. ${ }^{20}$ It has been found to be highly effective in reducing peridural scar formation 8 weeks after surgery in a canine laminotomy with discectomy model. ${ }^{20}$ The effectiveness of ADCON-L has also been demonstrated in clinical settings, and ADCON-L is marketed in most European countries, Australia, New Zealand, and Canada. ${ }^{19}$ This product, however, has not been applied in cases involving strabismus surgery.

The present study was conducted to assess the efficacy of ADCON-L in inhibiting adhesion and to evaluate the safety of using the product in situations involving strabismus surgery.

Subjects and methods

Sixteen white rabbits of both sexes, weighing $2.0-2.5 \mathrm{~kg}$, were selected for the study. The care and handling of the rabbits were in accordance with the Association for Research in Vision and Ophthalmology Resolution on the Use of Animals in Research and the policies in the "Guidelines for the Care and Use of Laboratory Animals" (National Institute of Health publication No 85-23, as revised in 1985). Each rabbit was anaesthetised with an intramuscular injection of ketamine $\mathrm{HCl}$ (20 mg/kg, Ketara, Yuhan, Kunpo, Korea) and xylazine (2 mg/kg, Rompun, Bayer Korea, Seoul, Korea).

\section{SURGERY}

Surgical antisepsis with polyvinylpyrrolidoneiodine (Betadine) was applied to the eyelids before each operation. After a limbal peritomy from 10 o'clock to 2 o'clock, the superior rectus muscle (SR) was isolated on a Jameson hook and intermuscular connections were dissected. The SR was then placed on a double armed 6-0 polyglactin suture (Vicryl, Ethicon, Somerville, NJ, USA) close to the insertion site and disinserted from the globe. The SR in both eyes was recessed $5 \mathrm{~mm}$ using a hangback 


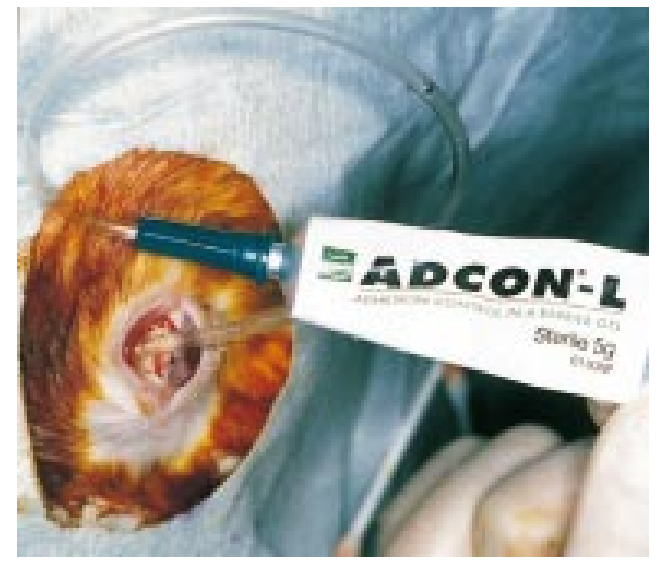

Figure 1 Photograph shows the procedure by which ADCON-L is injected after recession of superior rectus.

technique and the two sutures were tied together to make pole sutures. This technique enables easy evaluation of adhesion between the muscle and the sclera. A loop handle of 6-0 polyglactin suture was made around the pole sutures for future traction. ADCON-L of about $1 \mathrm{ml}$ was applied around SR in the right eyes (Fig 1) and the same amount of a balanced salt solution (BSS, Alcon, Fort Worth, TX, USA) was irrigated around the SR in the left eyes. The edges of the conjunctival peritomy were approximated with two simple interrupted 6-0 polyglactin sutures. At the end of each procedure, ofloxacin ointment was applied topically and $2 \mathrm{mg}$ of gentamicin was injected in the thigh muscle.

\section{POSTOPERATIVE PROCEDURES}

\section{Adjustment}

Four days postoperatively, the animals were reanaesthetised and operated on for adjustment in a randomised, masked fashion. A wide limbal peritomy from 8 o'clock to 4 o'clock was performed and each SR was adjusted. A dial tension gauge (DT-50, Teclock, Japan) or push-pull gauge (PP-705, $5 \mathrm{~g}, 500 \mathrm{~g}$, Teclock, Japan) was used to grasp the loop handle of the sutures connected to the muscle. The SR was moved anteriorly as much as possible, and the necessary force was measured with the gauge. A Castroviejo caliper was used for measurement of the length of adjustment. The length of adjustment was defined as the advanced distance from the recessed site. After the force and length of the adjustment were recorded each advanced SR was repositioned to the recessed site. The edges of the conjunctival peritomy were approximated with two simple interrupted 6-0 polyglactin sutures.

Seven days postoperatively, the rabbits were reanaesthetised and each SR was adjusted with the same procedure. The force and length of the adjustments were recorded. After the muscle was advanced, the separated pole sutures were tied together to permanently secure the muscle. The edges of the conjunctival peritomy were approximated with two simple interrupted $6-0$ polyglactin sutures. Postoperative care consisted of a daily application of ofloxacin ointment for 3 days after each procedure.

\section{Evaluation of adhesions}

At the times of adjustment, adhesion between the muscle, sclera, and conjunctiva was evaluated and recorded. The adhesion was classified as $\mathrm{SR} / \mathrm{C}$ ( $\mathrm{SR} /$ conjunctiva) if it was located above the $\mathrm{SR}$ and $\mathrm{SR} / \mathrm{S}$ (SR/sclera) when located below the SR. The severity of the adhesion was scored on a scale from 0 to 4 , where $0=$ no adhesion, $1=$ adhesion easily separable with blunt dissection with cotton tip applicator, $2=$ mild adhesion with freely dissectible plane, $3=$ dense adhesion with difficult dissection, and $4=$ non-dissectible plane.

\section{Measurement of disinsertional force}

Three weeks postoperatively, $4-0$ black silk was threaded through the SR close to the new insertion point and grasped by the push-pull gauge in 13 rabbits. The push-pull gauge was used to pull the $4-0$ black silk until disinsertion of the SR from the sclera was achieved. Disinsertional force, defined as the force necessary to disinsert the $\mathrm{SR}$, was measured and recorded.

\section{HISTOLOGICAL EXAMINATION}

One rabbit was sacrificed at postoperative 4 days, 7 days and 3 weeks and eyeballs including SR and conjunctiva were enucleated. The eyeball was examined microscopically using haematoxylin and eosin staining. Masson's trichrome staining was also performed to evaluate the degree of fibrous proliferation.

\section{STATISTICAL ANALYSIS}

A statistical analysis was performed to determine the effect of ADCON-L in preventing adhesion and delaying adjustment. The length of advancement, the force necessary for adjustment, and the disinsertional force were analysed using Student's $t$ test. The severity of the adhesions was analysed using Wilcoxon rank sum test.

\section{Results}

\section{ADIUSTABILITY}

At 4 days postoperatively, an adjustment was possible in all eyes treated with ADCON-L or BSS. At 7 days postoperatively, an adjustment was possible in all eyes treated with ADCON-L but in only six out of 13 eyes treated with BSS (Table 1).

FORCE AND LENGTH FOR ADJUSTMENT

At 4 days postoperatively, the average force and length of the adjustments were $70.30 \mathrm{~g}$ and $1.75 \mathrm{~mm}$, respectively, in eyes treated with BSS, and $48.00 \mathrm{~g}$ and $4.34 \mathrm{~mm}$, respectively, in eyes treated with ADCON-L (Table 1, Fig 2). At 7 days postoperatively, the average force and length of the adjustments were $145.00 \mathrm{~g}$ and $1.00 \mathrm{~mm}$, respectively, in eyes treated with BSS, and $79.10 \mathrm{~g}$ and $3.18 \mathrm{~mm}$, respectively, in eyes treated with ADCON-L (Table 1, Fig 2). There were statistically significant differences in the average force and length of the adjustments between eyes treated with BSS and eyes treated with ADCON-L at 4 and 7 days postoperatively $(\mathrm{p}=0.00)$. 
Table 1 Degree of adhesion, length of adjustment, and number of adjustable eyes in each group (mean (SD))

\begin{tabular}{|c|c|c|c|c|c|}
\hline \multirow[b]{2}{*}{ Group } & \multirow[b]{2}{*}{ Time } & \multicolumn{2}{|l|}{ Adhesion } & \multirow{2}{*}{$\begin{array}{l}\text { Length of } \\
\text { adjustment } \\
\text { (mm) }\end{array}$} & \multirow[b]{2}{*}{ No of eyes } \\
\hline & & $S R / C$ & $S R / S$ & & \\
\hline \multirow[t]{2}{*}{ BSS treated } & 4 days & $2.19(0.91)$ & $1.75(0.58)$ & $1.75(0.77)$ & 16 of 16 \\
\hline & 7 days & $3.79(0.43)$ & $3.71(0.47)$ & $1.00(1.08)$ & 6 of 13 \\
\hline \multirow[t]{2}{*}{ ADCON-L treated } & 4 days & $0.75(0.68)$ & $0.88(0.50)$ & $4.34(0.63)$ & 16 of 16 \\
\hline & 7 days & $1.87(0.77)$ & $2.33(0.49)$ & $3.18(1.32)$ & 13 of 13 \\
\hline
\end{tabular}

$\mathrm{SR} / \mathrm{C}=$ adhesion above the superior rectus muscle $(\mathrm{SR}), \mathrm{SR} / \mathrm{S}=$ adhesion below the SR. Scoring system of the adhesion: $0=$ no adhesion, $1=$ adhesion easily separable with blunt dissection with cotton tip, 2 = mild adhesion with freely dissectible plane, $3=$ dense adhesion with difficult dissection, and $4=$ non-dissectible plane.

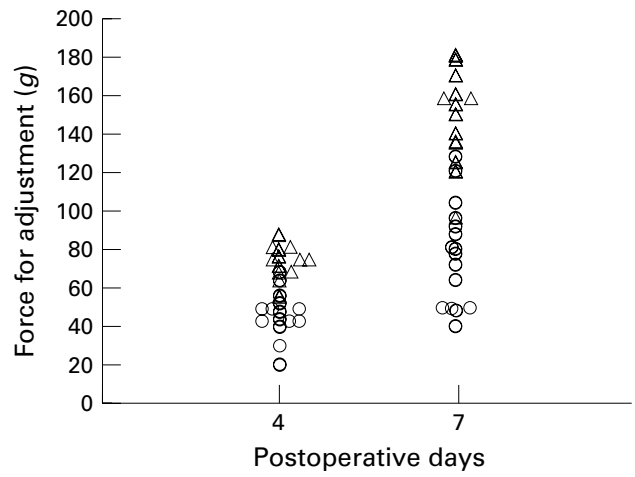

Figure 2 Scatter plot of measurements of force for adjustment at postoperative 4 and 7 days. The circles represent $A D C O N-L$ treated eyes and the triangles represent BSS treated eyes. (Mean (SD): 48.0 (11.3) in ADCON-L group, 70.3 (9.9) in BSS treated group at 4 days postoperatively; 79.1 (27.8) in ADCON-L group, 145.0 (31.8) in BSS treated group at 7 days postoperatively)

Degree of adhesion

In the eyes treated with ADCON-L, the mean score for adhesion between the conjunctiva and the muscle was 0.75 at 4 days postoperatively and 1.87 at 7 days postoperatively. In the eyes treated with BSS, the mean score for adhesion between the conjunctiva and the muscle was 2.19 at 4 days postoperatively and 3.79 at 7 days postoperatively (Table 1 ). The mean score for adhesion between the muscle and the sclera was 0.88 at 4 days postoperatively and 2.33 at 7 days postoperatively in eyes treated with ADCON-L and 1.75 and 3.71, respectively, in eyes treated with BSS (Table 1). These results suggest that ADCON-L helped to reduce postoperative adhesion $(p=0.00)$.

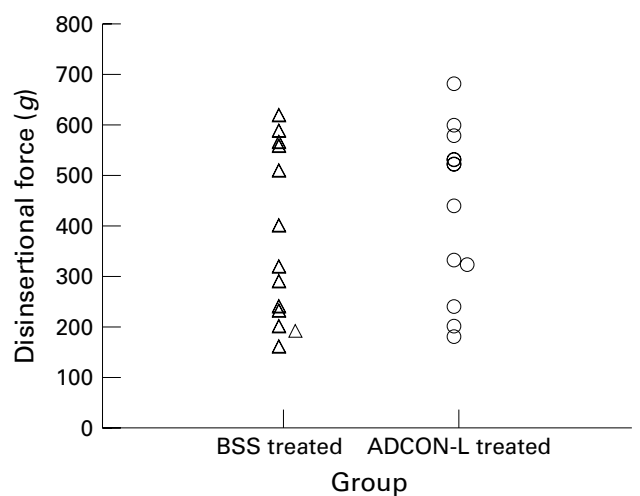

Figure 3 Scatter plot of disinsertional force at 3 weeks postoperatively in BSS treated and ADCON-L treated group (mean (SD): 431 (198) in ADCON-L group, 373 (174) in BSS treated group).
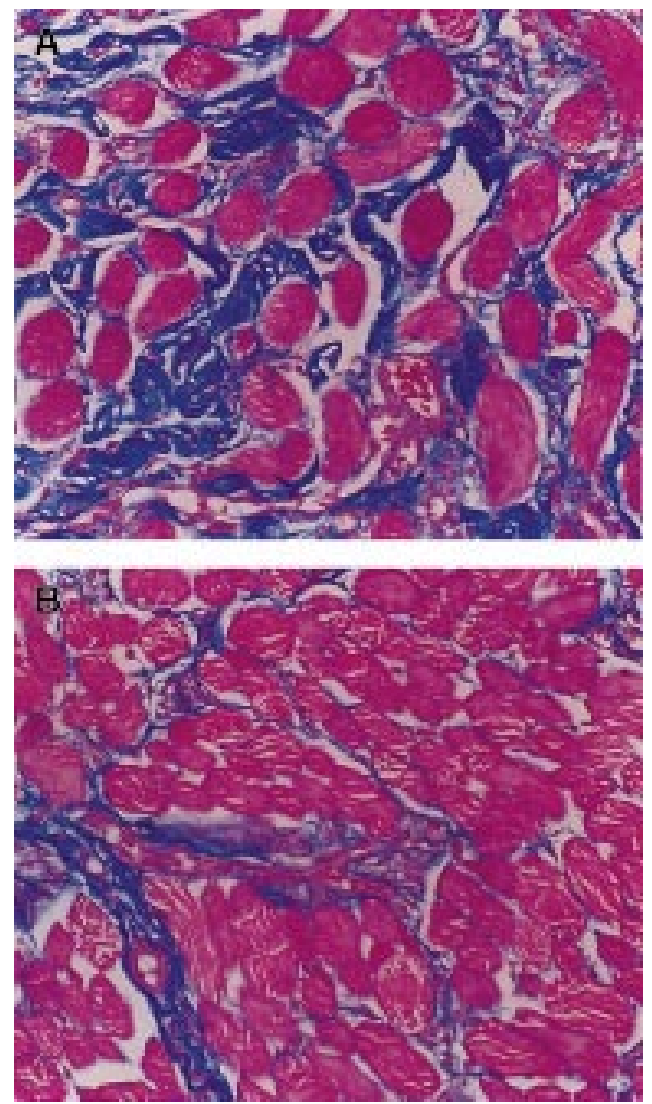

Figure 4 At 3 weeks postoperatively, marked fibrosis was observed surrounding the extraocular muscle $(A)$ in an eye treated with balanced salt solution while fibrosis was comparatively less in an eye treated with ADCON-L (B).

\section{Disinsertional force}

Disinsertional force was greater in eyes treated with ADCON than in eyes treated with BSS (Fig 3, mean (SD): 431 (198) in ADCON-L group, 373 (174) in BSS treated group). However, the difference was not statistically significant $(p=0.50)$.

\section{Histological examination}

Histological examination by light microscopy revealed less fibrosis and inflammation and no abnormality of the sclera or underlying ciliary body in eyes treated with ADCON-L (Fig 4). ADCON-L could not be demonstrated in ADCON-L group.

\section{Discussion}

Adhesion following strabismus surgery often affects the postoperative outcome and makes adjustment and dissection difficult in cases of reoperation. Although Howard and Smith have been able to delay the final adjustment up to 1 week postoperatively without additional materials, ${ }^{2}$ a variety of materials have been used in attempts to prevent postoperative adhesion following strabismus surgery in animal studies. Among these materials are silicone, supramid, polypeptide sleeve, viscoelastics, interceed, polyglactin 910 mesh, polytetrafluoroethylene (PTFE), mitomycin-C (MMC), and 5-fluorouracil (5-FU) ${ }^{8-18}$ However, it is yet to be definitely demonstrated that these materials reduce adhesion in humans, although findings 
from one clinical study with sodium hyaluronic acid suggest that it reduces the amount of force necessary to adjust a muscle. ${ }^{9}$ Furthermore, occurrences of serious complications related to 5-FU after glaucoma surgery have been reported. ${ }^{21}$ Similarly, there are reports of severe complications after the use of MMC as a medical adjunct to pterygium and glaucoma surgery. ${ }^{22}{ }^{23}$ And the marked forward migration of the muscle fibre at the later stage in MMC treated eyes is possibly caused by tissue damage resulting from the toxicity of $\mathrm{MMC}^{24}$

In contrast, $\mathrm{ADCON}-\mathrm{L}$ has been found to inhibit peridural scarring in cases involving lumbar discectomy in humans. It has also been shown to reduce the development of fibrotic peridural scarring in several animal models in previous investigations. ${ }^{20} 25$ And clinical trials using ADCON-L in lumbar discectomy procedures have been performed in Europe and in the United States. ${ }^{26}{ }^{27}$ Therefore, we conducted the present study to evaluate the efficacy of $\mathrm{ADCON}-\mathrm{L}$ as an adjunctive agent preventing adhesion after strabismus surgery.

Findings from the present study indicate that ADCON-L inhibits postoperative adhesion and facilitates adjustment following the recession surgery. The findings, taken from animal research, and clinical experience suggest that multiple factors are involved in the pathogenesis of postoperative scarring. ${ }^{17} \mathrm{Re}-$ gardless of the exact mechanisms of postoperative adhesion; however, the prevention or limitation of fibroblast proliferation seems to be a key factor in preventing adhesion formation. ${ }^{17}$ Our results suggest that the force required for the adjustment is associated with adhesion around the SR and are consistent with the hypothesis that the inhibition of postoperative adhesion may prolong the time available for postoperative adjustment of the muscle.

The precise mechanism by which ADCON-L reduces adhesion remains unclear. It has been shown that the glycosaminoglycan moiety of certain proteoglycans can establish boundaries for cellular migration both in vitro ${ }^{28}$ and in vivo. ${ }^{29}$ ADCON-L contains a carbohydrate polymer that has been shown to block the migration of fibroblasts in vitro. ${ }^{25} \mathrm{It}$ is therefore possible that ADCON-L acts in vivo by establishing an inhibitory barrier to invading fibroblasts, which results in less adhesion.

Although there was no statistical difference, disinsertional force was greater in the ADCON-L treated group than in the BSS treated group at 3 weeks postoperatively. Also, there was no detectable remnant of ADCON-L at 3 weeks postoperatively whereas ADCON-L remained in the operative field at 4 and 7 days postoperatively. Theses findings may indicate that the effect of ADCON-L on the prevention of adhesion is not maintained for 3 weeks postoperatively, although we did not evaluate the degree of adhesion.

There appear to be several advantages to using ADCON-L in strabismus surgery. Firstly, ADCON-L is non-toxic and does not induce granuloma formation because it is a sterile, absorbable gel matrix. ${ }^{20}$ Secondly, and more importantly, its antifibrotic properties are localised to the discrete area to which it is applied, so healing of adjacent tissues is not significantly affected. ${ }^{7}$ We were not able to identify any damage to the muscle fibres or the subconjunctival and scleral fibroblasts on histopathological examination, but toxic effects on ocular anterior segment tissue must be further evaluated. Lastly, ADCON-L is relatively easy to use and there is no risk of extrusion.

Indeed, at the beginning of this experiment, we were not sure whether ADCON-L could be effective in reducing scarring after strabismus surgery. Furthermore, we were uncertain about issues related to toxicity or other complications of ADCON-L. Because of this uncertainty, we performed an adjustment at 4 days postoperatively, at which time ADCON-L was found to be an effective and safe adjunct to adjustable strabismus surgery. Therefore, we performed a readjustment to assess its ability to facilitate adjustment in the same eye at 7 days postoperatively. However, we can not extrapolate the results of this study to those of an experiment in which the first adjustment had been performed at 7 days postoperatively.

Rabbits have little subconjunctival connective tissue, so the original recession surgery was performed with little bleeding. It therefore seems quite possible that the operative procedures in rabbit eyes would induce less adhesion postoperatively than in human eyes after strabismus surgery. In humans, it is essential to achieve complete haemostasis before applying ADCON-L to obtain its maximum effect.

In conclusion, $\mathrm{ADCON}-\mathrm{L}$ is of potential value in the prevention of adhesion and may be used as a means of providing two adjustments without complication for as long as 1 week after extraocular muscle surgery in rabbits.

Supported in part by a grant from the Chungbuk National University Hospital Research Fund, 2000.

1 Dunlap EA. Surgery of muscle adhesions and effects of multiple operations. Br f Ophthalmol 1974;58:307-12.

2 Howard CW, Smith AG. Use of adjustable sutures: a helpful modification. Ann Ophthalmol 1986;18:70-3.

3 Ruben ST, Elston JS. One stage adjustable sutures: practical aspects. Br f Ophthalmol 1992;76:675-7.

4 Morris RJ, Luff AJ. Adjustable sutures in squint surgery. $\mathrm{Br}$ f Ophthalmol 1992;76:560-2

5 Wisnicki HJ, Repka MX, Guyton DL. Reoperation rate in adjustable strabismus surgery. F Pediatr Ophthalmol Strabismus 1988;25:112-4.

6 Pratt-Johnson JA. Adjustable-suture strabismus surgery: a review of 255 consecutive cases. Can 7 Ophthalmol 1985;20:105-9.

7 Keech RV, Scott WE, Christensen LE. Adjustable suture strabismus surgery. F Pediatr Ophthalmol Strabismus 1987; 24:97-102.

8 Hwang J-M, Chang B-L. Combined effect of interceed and 5 -fluorouracil on delayed adjustable strabismus surgery. $\mathrm{Br}$ f Ophthalmol 1999;83:788-91.

9 Clorfeine GS, Parker WT. Use of healon in eye muscle surgery with adjustable sutures. Ann Ophthalmol 1987;19:215-

10 Shokida MF. Use of a silicone sheet for delayed adjustable strabismus surgery. Ophthalmic Surg 1993;24:486-8.

11 Elsas FJ, Gowda DC, Urry DW. Synthetic polypeptide sleeve for strabismus surgery. $\mathcal{F}$ Pediatr Ophthalmol Strabismus 1992;29:284-6.

12 Hwang J-M, Chang B-L. Use of physical barriers for delayed adjustable strabismus surgery: the effect of interceed and poyglactin 910 mesh. Br f Ophthalmol 1996; 80:759-62.

13 Hwang J-M, Chang B-L. Use of viscoat for delayed postoperative adjustable suture strabismus surgery in rabbits. Binocul Vis Strabismus $O$ 1996;11:137-42.

14 Hwang J-M, Chang B-L. Delayed reattachment of extraocular muscles in rabbits using thin polytetrafluoroethylene. Ophthalmic Surg Lasers 1997;28:59-64. 
15 Searl SS, Metz HS, Lindahl KJ. The use of sodium hyaluronate as a biologic sleeve in strabismus surgery. Ann nate as a biologic sleeve
Ophthalmol 1987;19:259-68.

16 Cruz OA. Evaluation of mitomycin to limit postoperative adhesions in strabismus surgery. 7 Pediatr Ophthalmol Strabismus 1996;33:89-92.

17 Brooks SE, Ribeiro G, Archer SM, et al. Fat adherence syndrome treated with intraoperative mitomycin-C: a rabbit model. F Pediatr Ophthalmol Strabismus 1996;33:21-7. 18 Andreo LK, Uyemura MJ, Enzenauer RW. 5-Fluorouracil Ophthalmol Strabismus 1997;34:107-10.

19 Jack D. Sticky situations: surgical adhesions and adhesives. Lancet 1998;351:118.

20 Einhaus SL, Robertson JT, Dohan FC, et al. Reduction of peridural fibrosis after lumbar laminotomy and discectomy in dogs by a resorbable gel (ADCON-L). Spine 1997;22: $1440-7$.

21 Heuer DK, Parrish RK, Gressel MG, et al. 5-Fluorouracil and glaucoma filtering surgery. Ophthalmology 1986;93:

22 Rubinfeld RS, Pfister RR, Stein RM, et al. Serious complications of topical mitomycin- $\mathrm{C}$ after pterygium surgery. Ophthalmology 1992;99:1647-54.
23 Kitazawa Y, Kawase K, Matsushita H, et al. Trabeculectomy with mitomycin: a comparative study with fluorouracil. Arch Ophthalmol 1991:109:1693-8.

24 Ohtsuki H, Hasebe S, Okuda Y, et al. Is mitomycin effective in preventing muscle migration after hang-back recession in a rabbit model? Ophthalmologica 1997;211:373-9.

25 Petersen J, Russell L, Andrus K, et al. Reduction of extraneural scarring by ADCON-T/N after surgical intervention. Neurosurgery 1996;38:976-84.

26 Ross JS, Robertson JT, Frederickson RCA, et al. Association between peridural scar and recurrent rdicular pain after umbar discectomy: magnetic resonance evaluation. Neurosurgery 1996;38:855-63.

27 Tribolet N, Porchet F, Lutz TW, et al. Clinical assessment of a novel antiadhesion barrier gel: prospective, randomized, multicenter, clinical trial of ADCON-L to inhibit postoperative peridural fibrosis and related symptoms after lumbar discectomy. Am f Orthop 1998;27:111-20.

28 Snow DM, Lemmon V, Carrino DA, et al. Sulfated proteoglycans in astroglial barriers inhibit neurite outproteoglycans in astroglial barriers inhibit

29 Brittis PA, Canning DR, Silver J. Chondroitin sulfate as a Brittis PA, Canning DR, Silver J. Chondroitin sulfate as a
regulator of neuronal pattering in the retina. Science 1992; 255:733-6. 